\title{
Effect of Debris Accumulation on Machining Speed in EDM
}

\author{
Serkan Cetin*, Akira Okada* and Yoshiyuki Uno* \\ (Received January 16, 2003) \\ * Department of Mechanical Engineering, Okayama University, Okayama 700-8530, Japan
}

\begin{abstract}
This paper shows the effect of electrode jump height on machining speed and depth in deep machining for linear motor equipped electrical discharge machining. A new definition named "Machining speed break point" is introduced from the experiments. This new definition is then theoretically calculated from a proposed electrode jump and debris exclusion model, and compared with the experimental results. Additionally, an algorithm is developed to calculate the accumulation of debris in machining gap. The algorithm results showed that the debris concentration in gap rises suddenly before the machining speed break point.
\end{abstract}

Key words: EDM, electrode jump, machining speed, debris exclusion, debris accumulation

\section{INTRODUCTION}

Linear motor equipped die-sinking electrical discharge (ED) machines are reported to be faster and more stable in machining compared to the conventional ED machines. It is further reported that, debris exclusion and no-flush machining even in deep machining are improved by the high-speed jump motion of the electrode ${ }^{1), 2)}$. There are also researches about the role of debris in gap, alternative jump operations and observing machining debris during electrode jump ${ }^{3)-7}$. However, neither of these studies includes nor discusses the study of electrode jump motion and its effects on the machining speed for higher electrode jump rates.

Recently, with the help of high speed linear motor servo systems, higher electrode jump speeds can easily be obtained, which could not be realized before with the conventional ball screw type of ED machines. Therefore, there is a need to investigate the effects of electrode jump parameters on the machining speed so that further improvements could be done to obtain faster and more stable machining.

The effect of electrode jump height on machining speed and depth is reported and discussed in this paper. A new definition named "Machining speed break point" in die sinking EDM is introduced from the experiments. Likewise, a jump and debris exclusion model is proposed where the "Machining speed break point" is theoretically calculated. Finally, an algorithm to simulate the debris concentration rise in the machining gap is developed. Both in the model and the algorithm, the theoretical results are compared with the experimental ones.

\section{EXPERIMENTAL SETUP}

Different jump motions of the electrode for different electrode jump speeds and jump times were recorded with a laser displacement sensor and a digital data recorder (Fig.1).

A linear motor equipped ED machine was used for all the experiments. Cylindrical copper and graphite electrodes of $10 \mathrm{~mm}$ in diameter were used. The workpiece material was die-steel SKD61 (in JIS specification). All the experiments were done with no-flush condition. The machining parameters were set mainly for rough machining (Table 1).

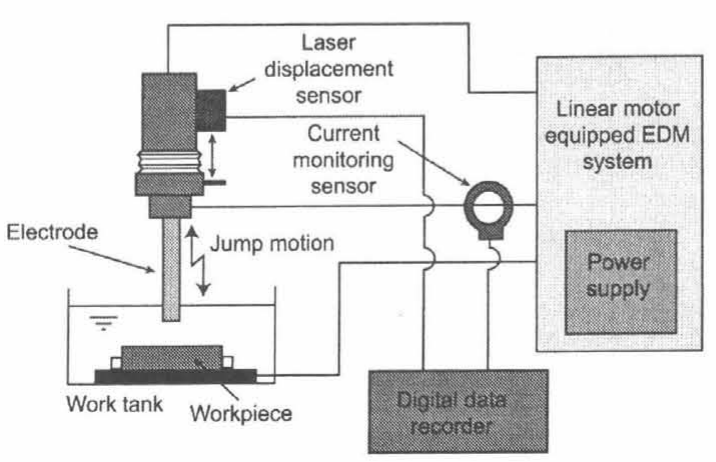

Fig. 1 Schematic view of experimental setup 
Table 1 Machining conditions

\begin{tabular}{l|l}
\hline Electrode shape \& material & $\begin{array}{l}\phi 10 \mathrm{~mm} \text { - Copper } \\
\phi 10 \mathrm{~mm} \text { - Graphite }\end{array}$ \\
\hline Dielectric fluid & Kerosene type fluid \\
\hline Workpiece material & SKD61 (JIS) \\
\hline Discharge current $\left(\mathrm{i}_{\mathrm{e}}\right)$ & $10,24,28,32 \mathrm{~A}$ \\
\hline Discharge duration $\left(\mathrm{t}_{\mathrm{e}}\right)$ & $110,200 \mu \mathrm{s}$ \\
\hline Pulse interval time $\left(\mathrm{t}_{\mathrm{o}}\right)$ & $45,90 \mu \mathrm{s}$ \\
\hline Jump time $\left(\mathrm{t}_{\mathrm{j}}\right)$ & $0.08,0.10,0.12,0.14$, \\
\hline Real machining time $\left(\mathrm{t}_{\mathrm{rm}}\right)$ & $0.16,0.30,0.50 \mathrm{~s}$ \\
\hline Jump speed $\left(\mathrm{J}_{\mathrm{s}}\right)$ & $0.3,0.5,0.6,0.9,1.2 \mathrm{~s}$ \\
\hline & $0,3,9,18,27$,
\end{tabular}

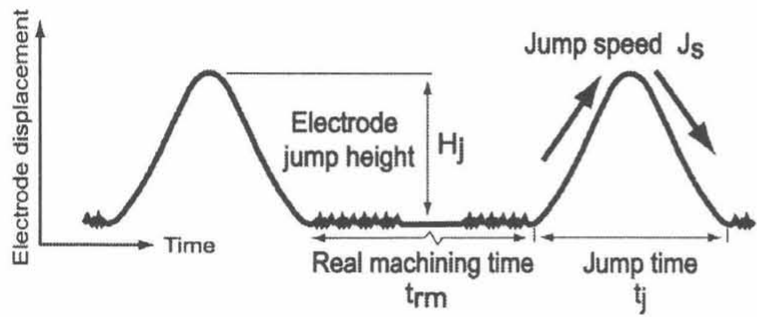

Fig. 2 Schematic explanation of electrode jump parameters

\section{ELECTRODE JUMP PARAMETERS}

Electrode jump motion and all the parameters that control the electrode motion during the jump are illustrated in Fig.2. Here, $H_{j}$ is the electrode jump height where the electrode retracts to a certain maximum height. Jump time $\left(t_{j}\right)$ is the duration for the electrode to complete one full jump. Real machining time $\left(t_{r m}\right)$ indicates the duration between two successive electrode jumps. Lastly, jump speed $\left(J_{s}\right)$ is the maximum speed of the electrode during the jump. Parameters $t_{j}, t_{r m}$ and $J_{s}$ can be set up independently as auxiliary parameters within the machine software.

\subsection{Effect of Electrode Jump Speed on} Machining Speed

Figure 3 displays the effect of electrode jump speed on the average machining speed, where the relationships between machining depth and different electrode jump speeds are shown. Except for electrode jump speed $0 \mathrm{~m} / \mathrm{min}$, the machining speeds are quite close to each other. This result shows that the electrode jump speed alone does not have a strong effect on the machining speed.

3.2 Effect of Electrode Jump Height on Machining Speed and Depth

Figure 4 illustrates the relationships between machining depth and electrode jump height for

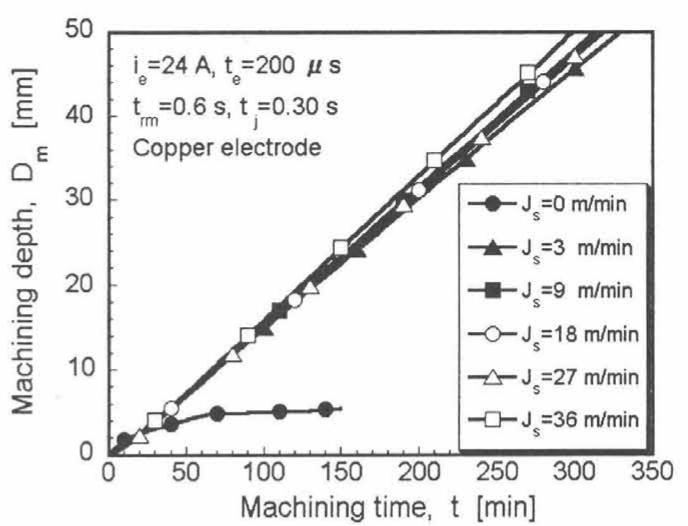

Fig. 3 Machining depth for different electrode jump speeds

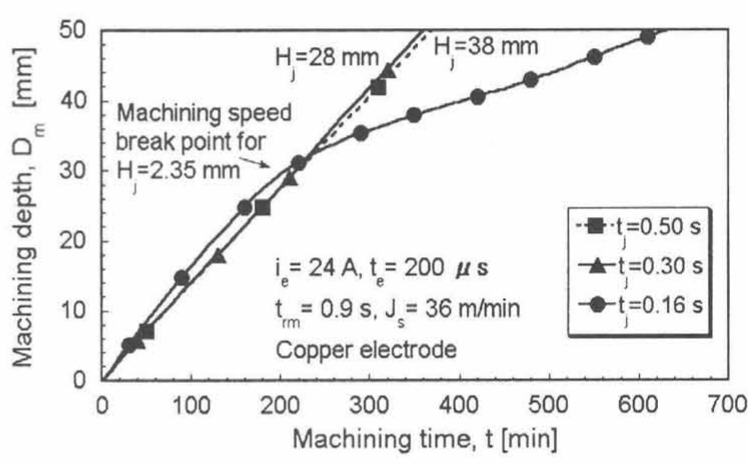

Fig. 4 Machining speed break point

various jump times. For shorter jump height, machining is faster up to a certain depth after which the machining speed slows down. From now on, this point of speed change will be termed as "Machining speed break point", and the depth where it occurs will be termed as "Machining speed break point depth" $\left(D_{m s b p}\right)$. Machining speed break points are not observed for higher electrode jumps, since debris exclusion from the machining gap becomes easier as the jump of the electrode becomes higher.

\section{THEORETICAL ANALYSIS OF MACHINING SPEED BREAK POINT DEPTH}

As stated in the previous section, the machining speed break point depth has a significant importance in deep machining by determining the machining speed and the total machining time for a given depth of work. Therefore, in this section, an electrode jump and debris exclusion model is proposed to explain the phenomenon of machining speed break point. A critical machining depth, 
which represents the start of excess debris accumulation in working gap, is defined, theoretically calculated, and then compared with the experimentally defined machining speed break point depth.

\subsection{Model of Electrode Jump and Debris Exclusion}

The efficiency of jump flushing is strongly dependent on the volume of fluid that is flowing in and out of the working area. Therefore, the volume created by the up stroke movement of the electrode during the jump is important and defined as the "jump volume" $\left(V_{j}\right)$. The jump volume $\left(V_{j}\right)$ is filled and emptied repeatedly with the working fluid during the electrode jumps (Fig.5(a)).

Figure 5(b) shows the volume of fluid that is ejected from volumes $V_{j}$ and $V_{A}$, where $V_{A}$ is the machining gap volume up to the jump height. Here, the ejected fluid volume is presented as volume B $\left(V_{B}\right)$, whereas the height of the ejected fluid volume is termed as the "side gap fluid height" $\left(H_{s g f}\right)$. In this model, all the debris particles inside volume $V_{B}$, were assumed to be collected into the volumes $V_{j}$ and $V_{A}$ by the effective suction of the jump movement, and then again pumped back into volume $V_{B}$ evenly during jumping. Moreover, due to the assumption that all the debris particles are trapped inside the volume $V_{B}$, the amount of debris disposed out of the hole is proportional to the length of $H_{o}$, where $H_{o}$ is the part of the side gap fluid height going out of the workpiece.

Three cases where machining depth $\left(D_{m}\right)$ is shorter, equal or longer than $H_{s g f}$ are illustrated in Fig.6. When the machining depth is longer or equal to $H_{s g}$, there will be no debris disposal from the gap. Thus, it is possible to define the depth where the machining depth equals to $H_{s g f}$ as the critical machining depth $\left(D_{c}\right)$, due to the start of excess debris accumulation in the machining gap.

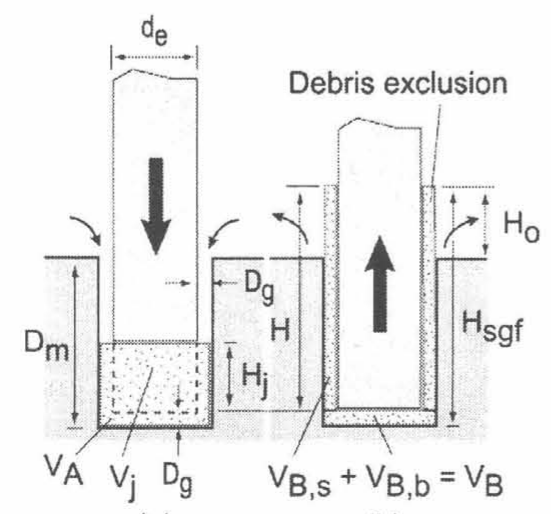

(a)

(b)

Fig.5 Schematic explanation of jump volume $\left(V_{j}\right)$ and side gap fluid height $\left(H_{s g f}\right)$
The side gap fluid height $\left(H_{s g f}\right)$ and so the critical machining depth $\left(D_{c}\right)$ can be geometrically calculated in short as follows:

From Fig.5(a) and (b),

$$
\begin{aligned}
& V_{B}=V_{j}+V_{A} \\
& V_{B}=V_{B, b}+V_{B, s}
\end{aligned}
$$

where $V_{B, b}$ and $V_{B, s}$ are the bottom and side volumes of $V_{B}$, respectively.

Solving the above equations for $H$, where $H$ is the length of side gap fluid volume above volume $V_{B, b}$ :

$$
H=H_{j} \frac{\left(d_{e}+2 D_{g}\right)^{2}}{\left(d_{e}+2 D_{g}\right)^{2}-d_{e}{ }^{2}}
$$

$D_{g}$ and $d_{e}$ represent the gap dimension between the workpiece and electrode per side and the diameter of cylindrical electrode, respectively.

Lastly, from Figs.5 and 6, the critical machining depth and the side gap fluid height are calculated as:

$$
D_{c}=H_{s g f}=H+D_{g}
$$

Here in this model, the electrode shape and the machined hole are assumed uniform and cylindrical. The bottom and side gap distances between the electrode and workpiece are also assumed uniform and equal. Furthermore, debris particles are considered as equally distributed within the gap without any precipitation. The debris concentration is taken as zero for fresh dielectric fluid entering the hole, and there are no debris particles transferring between the fresh dielectric and the fluid of the jump volume. In real applications, it is known that the bubble expansion pressure also excludes debris during machining. However, in this model, the phenomenon was disregarded to simply the model and calculations. Furthermore, the effect of electrode wear is neglected in the model.

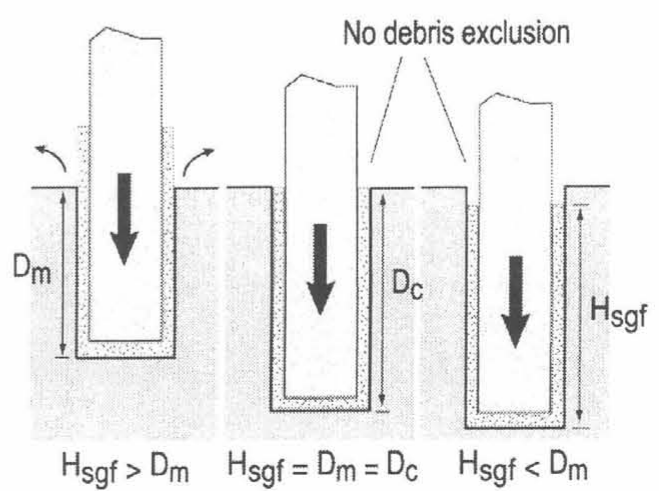

Fig.6 Definition of critical machining depth $\left(D_{c}\right)$ 


\subsection{Comparison of Theoretical and Experimental Results}

Figure 7 shows the calculated critical machining depths $\left(D_{c}\right)$ with respect to various jump heights. The values of the side gap used in the calculations are $0.19,0.18,0.17,0.16$ and $0.16 \mathrm{~mm}$ for jump height $2.35,1.35,0.75,0.35$ and $0.12 \mathrm{~mm}$, respectively. It is clear that the critical machining depth increases with jump height. Also the results in Fig.8, which were obtained experimentally, show the same behavior in which the machining speed break point depth increases with increasing electrode jump height. Figure 9 represents the relation between the calculated and experimental results more clearly.

In the same respect, Table 2 shows some other results of the calculated critical machining depths $\left(D_{c}\right)$ and experimentally found out machining speed break point depths $\left(D_{m s b p}\right)$ for different machining conditions. Apparently, the proposed model fits with the experimental results in a quite acceptable range for the given assumptions.

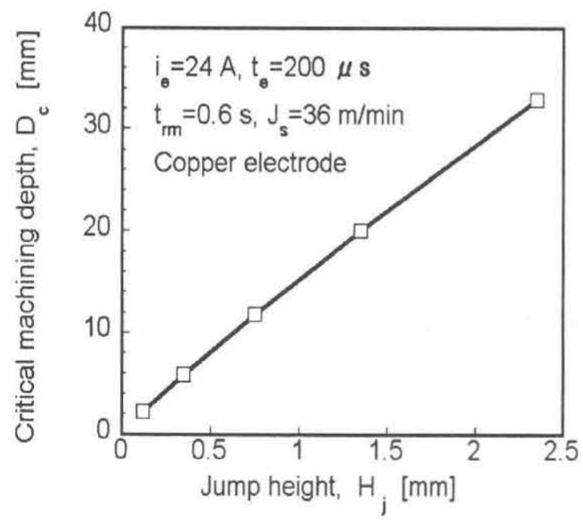

Fig.7 Relation between critical machining depth and electrode jump height

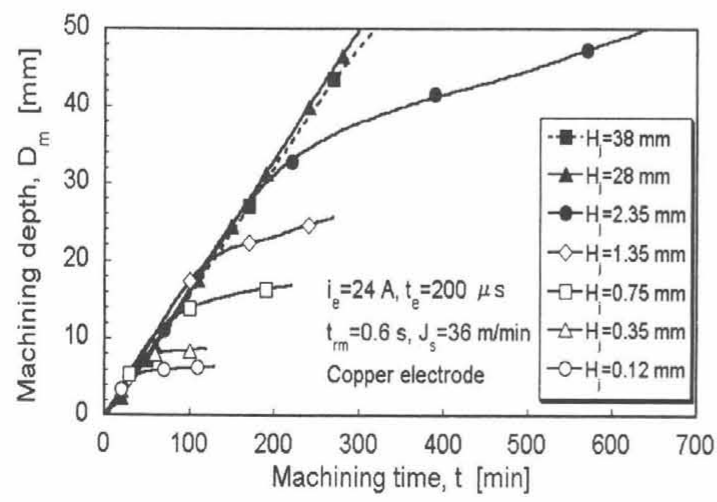

Fig.8 Relationship between machining depth and electrode jump height

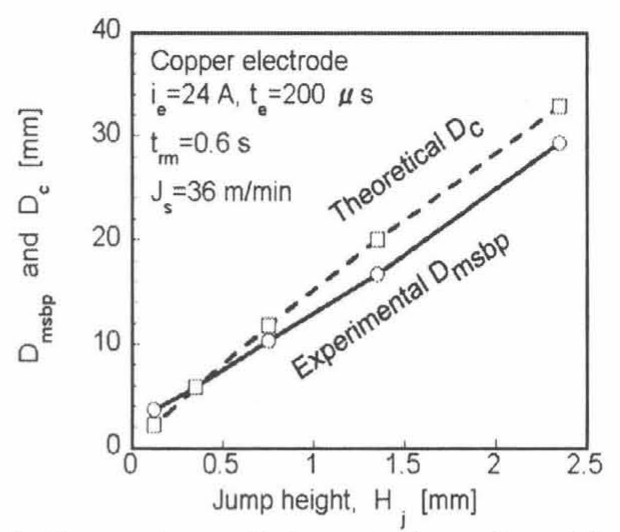

Fig.9 Comparison of theoretical results with experimental results for different electrode jump heights

Table2 Comparison of $D_{c}$ with $D_{m s b p}$ for different machining conditions

\begin{tabular}{|c|c|c|c|c|}
\hline \multirow{2}{*}{$\begin{array}{l}\overline{0} \\
\text { Oे }\end{array}$} & $\begin{array}{l}\text { Machining } \\
\text { conditions }\end{array}$ & $\begin{array}{l}\text { Average } \\
\text { gap/side } \\
(\mathrm{mm})\end{array}$ & $\underset{(\mathrm{mm})}{D_{c}}$ & $\begin{array}{l}D_{m s b p} \\
(\mathrm{~mm})\end{array}$ \\
\hline & $\begin{array}{c}\mathrm{i}_{\mathrm{e}}=10 \mathrm{~A}, \mathrm{t}_{\mathrm{e}}=100 \mu \mathrm{s}, \\
\mathrm{H}_{\mathrm{j}}=0.35 \mathrm{~mm}\end{array}$ & 0.24 & 4.1 & 4.3 \\
\hline \multirow{3}{*}{ 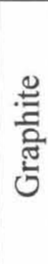 } & $\begin{array}{c}\mathrm{i}_{\mathrm{e}}=28 \mathrm{~A}, \mathrm{t}_{\mathrm{e}}=80 \mu \mathrm{s}, \\
\mathrm{H}_{\mathrm{j}}=0.35 \mathrm{~mm}\end{array}$ & 0.17 & 5.6 & 6.4 \\
\hline & $\begin{array}{c}\mathrm{i}_{\mathrm{e}}=28 \mathrm{~A}, \mathrm{t}_{\mathrm{e}}=80 \mu \mathrm{s} \\
\mathrm{H}_{\mathrm{j}}=1.35 \mathrm{~mm}\end{array}$ & 0.18 & 20.0 & 18.5 \\
\hline & $\begin{array}{c}\mathrm{i}_{\mathrm{e}}=32 \mathrm{~A}, \mathrm{t}_{\mathrm{e}}=200 \mu \mathrm{s}, \\
\mathrm{H}_{\mathrm{j}}=0.35 \mathrm{~mm}\end{array}$ & 0.20 & 4.8 & 4.4 \\
\hline
\end{tabular}

\section{ALGORITHM OF DEBRIS ACCUMULATION IN GAP}

\subsection{Developing the Algorithm}

This section introduces an algorithm to calculate the debris accumulation in machining gap. The algorithm is based on the model that was developed in the previous section by assuming that debris generation occurs only in the bottom gap between the electrode and the workpiece.

As presented before in Fig.8, the machining speed is almost constant up to machining speed break point. Thus, the debris generation rate can also be assumed linear up to the machining speed break point and calculated as:

$$
m_{t d}=\Delta m_{w}+\Delta m_{e}
$$
where

$m_{t d}:$ total mass of generated debris

$\Delta m_{w}$ : change of workpiece mass up to $D_{m s b p}$

$\Delta m_{e}$ : change of electrode mass up to $D_{m s b p}$.

From the total machining time up to machining 
break point $\mathrm{v}\left(t_{t m}\right)$, the total real machining time up to machining break point $\left(t_{\text {trm }}\right)$ can be calculated as:

$$
{ }_{t r m}=\frac{{ }_{t m}{ }^{t}{ }_{r m}}{{ }^{{ }_{r m}}+{ }{ }_{j}}
$$

Hence from Eq. (5) and (6), the total number of real machining time intervals $\left(N_{r m t}\right)$ and the debris generated for only one real machining time interval $\left(\Delta m_{g}\right)$ are:

$$
\begin{aligned}
& N_{r m t}=\frac{t_{t r m}}{t_{r m}} \\
& \Delta m_{g}=\frac{m_{t d}}{N_{r m t}}
\end{aligned}
$$

Figure 10 shows the schematic definitions of the parameters used in the algorithm to find the debris accumulation in the gap during machining. Here, $m_{l}$ is the mass of debris in the gap just after a complete electrode jump. As the electrode retracts to its maximum position, the mass of debris that is collected into volumes $V_{j}$ and $V_{A}$ is referred as $m_{2}$. Both $m_{3 s}$ and $m_{3 b}$ are the masses of debris remaining just after the electrode jump in the side and bottom gap volumes $V_{3 s}$ and $V_{3 b}$, respectively. On the other hand, $m_{3 e}$ represents the mass of debris disposed from the hole with the jump flush. Debris concentrations $c_{1}, c_{2}$, and $c_{3}$ are assumed uniform inside volumes $\quad\left(V_{j}+V_{A}\right)$ and $V_{3}$.

The formulation of the algorithm continues from Fig. 10 as

$$
\begin{aligned}
& m_{2}=m_{1}+\Delta m_{g} \\
& m_{3}=m_{3 s}+m_{3 b}
\end{aligned}
$$

where $m_{3}$ is the total mass of debris remaining in the gap after the electrode jump.

According to the assumption that the debris is trapped in volumes $\left(V_{j}+V_{A}\right)$ and $V_{3}$, the debris concentrations of these volumes can also be assumed equal $\left(c_{2}=c_{3}\right)$, from where $m_{3 b}$ and $m_{3 s}$ can be calculated by Eqs. (11) and (12).

$$
\begin{aligned}
& m_{3 b}=\frac{V_{3 b}}{\left(V_{j}+V_{A}\right)} m_{2} \\
& m_{3 s}=\frac{V_{3 s}}{\left(V_{j}+V_{A}\right)} m_{2}
\end{aligned}
$$

In Eq. (12), $V_{3 s}$ is a function of machining depth. In order to find $V_{3 s}$, the machining depth for one real machining time interval $\left(D_{r m t}\right)$ should be calculated first by

$$
D_{r m t}=\frac{D_{m s b p}}{t_{t m}} t_{r m}
$$

With the help of Eq. (13), the side gap volume $\left(V_{3 s}\right)$ can be defined for each real machining time interval. To simplify the formulation, the real machining time intervals will be numbered from the start of the machining so that each successive interval will be denoted by the machining depth increment number $(n)$. Thus, $V_{3 s}$ for any machining depth can be given as

$$
V_{n, s}=n A_{s g} D_{r m t} \quad \text { for } \mathrm{n}=1,2,3, \ldots
$$

where $A_{s g}$ is the total projected side gap area of the machined hole.

Figure 11 illustrates the formulated nodes, and the mass and concentration variation of the debris in gap according to the algorithm during machining. The general equations can be derived from Eqs. (9) and (10) as

$$
\begin{aligned}
& m_{2 n}=m_{2 n-1}+\Delta m_{g} \\
& m_{2 n+1}=m_{(2 n+1), s}+m_{(2 n+1), b}
\end{aligned}
$$

for $\mathrm{n}=1,2,3 \ldots$.

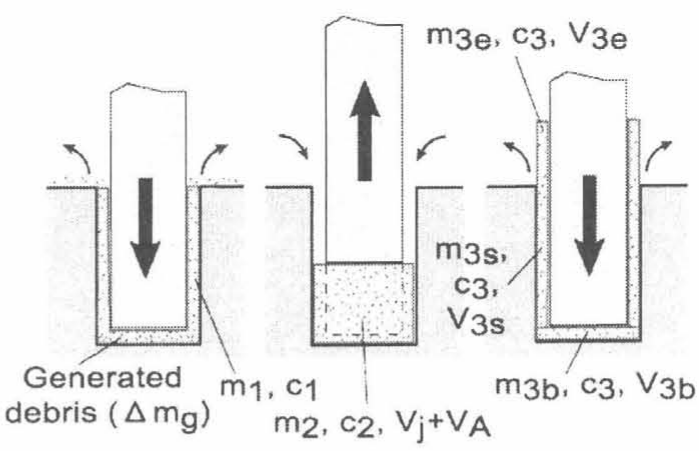

Fig.10 Schematic presentation of debris mass, concentration and volume parameters in algorithm

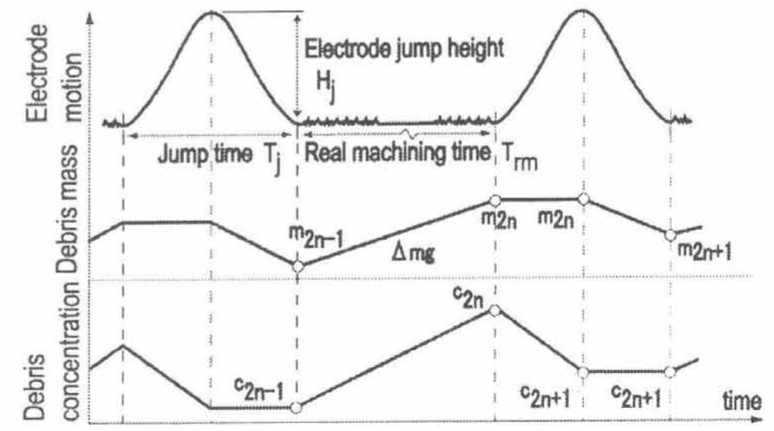

Fig.11 Schematic presentation of developed algorithm 


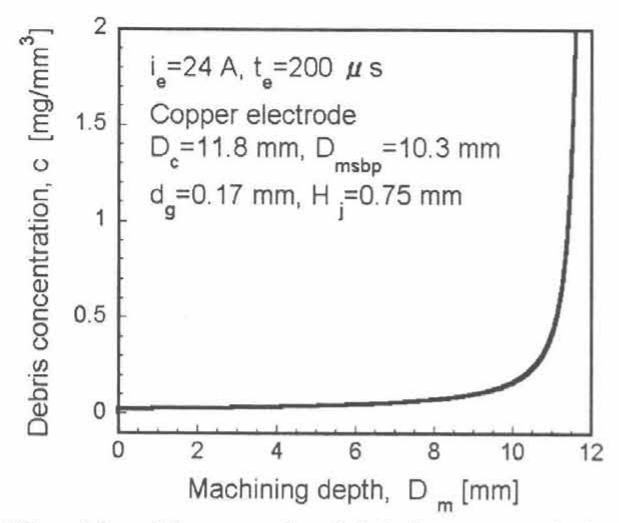

Fig.12 Algorithm result of debris accumulation inside gap for $\mathrm{H}_{\mathrm{j}}=0.75 \mathrm{~mm}$

Lastly, the concentration of the debris in the gap can be calculated by the help of Eq. (2), (15) and (16) as:

$$
c_{(2 n-1)}=\frac{m_{(2 n-1), b}+m_{(2 n-1), s}}{V_{b}+V_{(2 n-1), s}}
$$

for $\mathrm{n}=1,2,3 \ldots$.

\subsection{Calculation and Results of Algorithm}

The mass and concentration of the debris in the gap was calculated with a computer program for $n<N_{r m t}$. Figure 12 shows the graphical results of the developed algorithm for electrode jump height $0.75 \mathrm{~mm}$. Apparently from the figure, the debris concentration rises up evidently just before the critical machining depth. Thus, the developed algorithm shows that the drop in machining speed after the machining speed break point is due to the excess debris accumulation in the machining gap.

Also similar rises in debris concentration were obtained for different electrode jump heights.

\section{CONCLUSION}

The effect of electrode jump height on machining speed and depth in linear motor equipped die-sinking EDM was investigated. It was experimentally found out that electrode jump height plays a more important role compared to electrode jump speed in deep machining. A new definition named machining speed break point was introduced from the experiments, which was also derived from a proposed electrode jump and debris exclusion model. The developed model was capable to explain the drop in the machining speed after the machining speed break point in terms of excess debris accumulation in machining gap. Hence, an algorithm was developed to calculate and simulate the debris concentration in the machining gap. The numerical results agreed well with the experimental results, where debris concentration increases drastically just before the machining speed break point depth.

\section{REFERENCES}

1) KANEKO, Y., and YAMADA, H., 2000, "Performance of Linear Motor Equipped Die-Sinking EDM", International Journal of Electrical Machining, No. 5, pp. 59-64.

2) WATANABE, Y., 2002, "Factor for Speed-Up of Rib Machining", International Journal of Electrical Machining, No. 7, pp. 5-6.

3) SCHUMACHER, B.M., 1990, "About the Role of Debris in the Gap during Electrical Discharge Machining", CIRP Annals, 39/1, pp. 197-199.

4) MASUZAWA, T., and HEUVELMAN, C., J., 1985, "Study on the Flushing in EDM - Self Flushing Method", Journal of the Japan Society for Precision Engineers, 51, No. 7, pp. 112-118.

5) KANEKO, T., and TSUCHIYA, M., 1997, "Observation of behavior of Machining Products in Die-sinking EDM by using High-speed VTR", International Journal of Electrical Machining, No.2, pp. 37-42.

6) MASUZAWA, T. et al., 1992, "Improved Jet Flushing for EDM", Annals of the CIRP, Vol. 41/1/1992, pp. 239-242.

7) KUNIEDA, M. and YANATORI, K., 1997, "Study on Debris Movement in EDM Gap", International Journal of Electrical Machining, No. 2, pp. 43-49. 